\title{
Erratum to: A novel thermostable protein-tag: optimization of the Sulfolobus solfataricus DNA-alkyl-transferase by protein engineering
}

\author{
Antonella Vettone $^{1} \cdot$ Mario Serpe $^{1} \cdot$ Aurelio Hidalgo $^{2} \cdot$ José Berenguer $^{2} \cdot$ \\ Giovanni del Monaco $^{1} \cdot$ Anna Valenti $^{1} \cdot$ Mosé Rossi $^{1} \cdot$ Maria Ciaramella $^{1}$. \\ Giuseppe Perugino ${ }^{1}$
}

Published online: 14 December 2015

(C) Springer Japan 2015

\section{Erratum to: Extremophiles \\ DOI 10.1007/s00792-015-0791-9}

In the original publication, in Fig. 4, parts $\mathrm{c}$ and d were inadvertently not included. The correct version of Fig. 4 is given in this Erratum.

The online version of the original article can be found under doi:10.1007/s00792-015-0791-9.

Giuseppe Perugino

giuseppe.perugino@ibbr.cnr.it

1 Institute of Biosciences and BioResources, National Council of Research of Italy, Via P. Castellino 111, 80131 Naples, Italy

2 Centro De Biología Molecular Severo Ochoa, Nicolás Cabrera 1, Cantoblanco, 28049 Madrid, Spain 

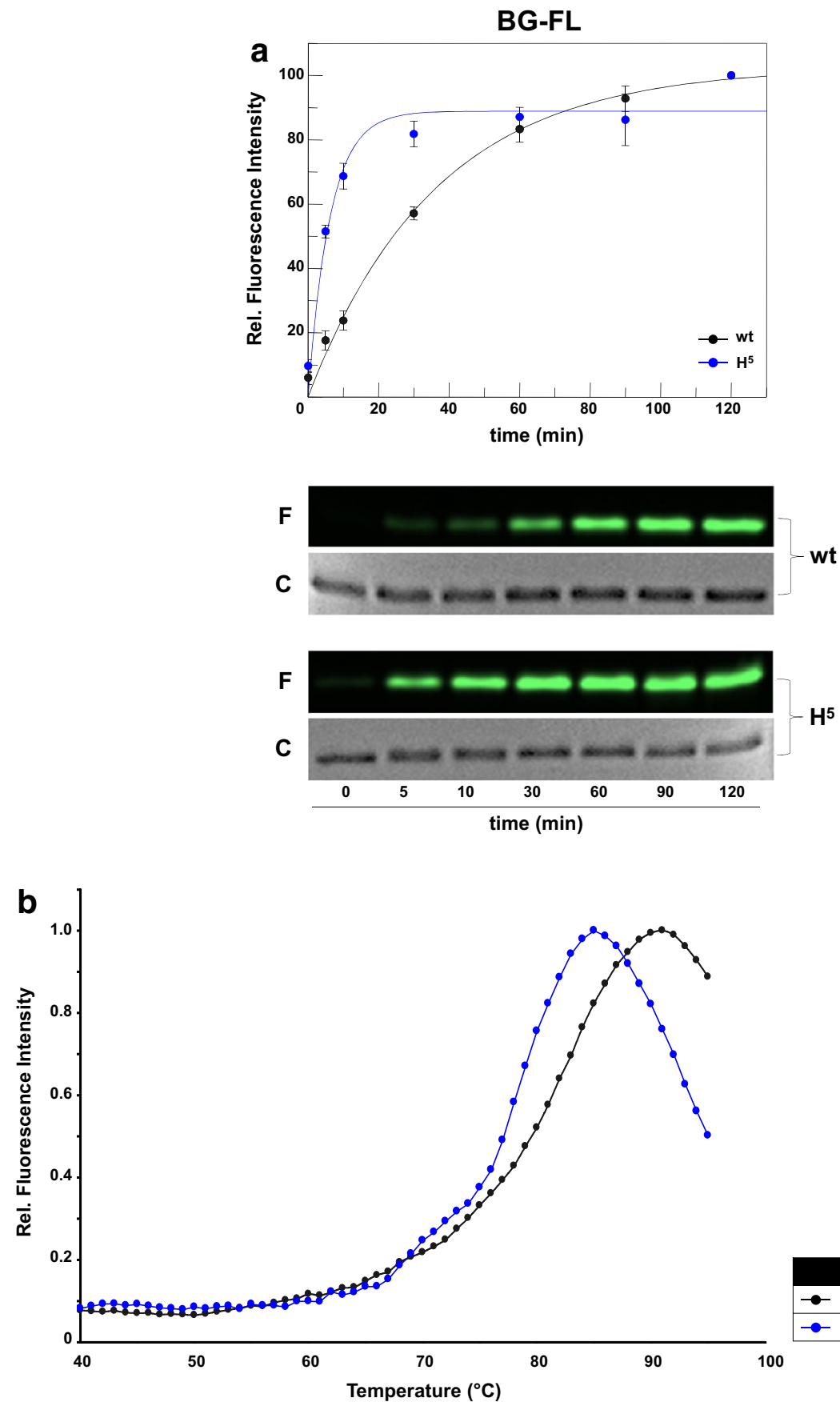

$\mathbf{T}_{\mathrm{m}}\left({ }^{\circ} \mathbf{C}\right)$ notes

- \begin{tabular}{c|c|l} 
wt & $80.0 \pm 0.4$ & Perugino et al. 2015
\end{tabular}

\begin{tabular}{ll|l|l}
$\bullet$ & $\mathbf{H}^{5}$ & $75.1 \pm 0.6$ & this study
\end{tabular} 

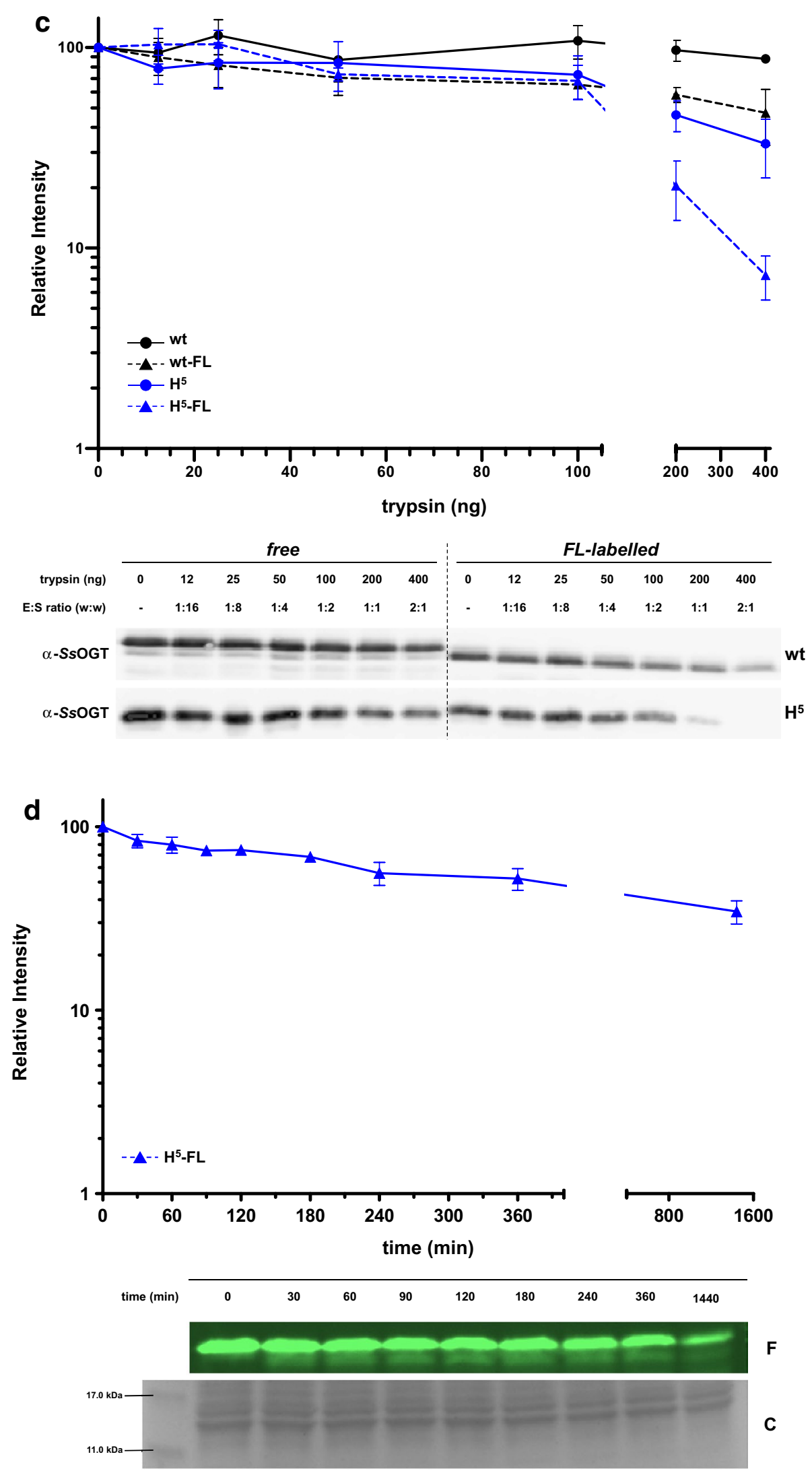